\title{
A IMPORTÂNCIA DA CONCEPÇÃO CULTURAL DE LEI FUNDAMENTAL PARA O DESENVOLVIMENTO DO SABER JURÍDICO CONSTITUCIONAL
}

\author{
THE IMPORTANCE OF A CULTURAL CONCEPTION OF \\ FUNDAMENTAL LAW FOR THE DEVELOPMENT OF \\ CONSTITUTIONAL LEGAL KNOWLEDGE
}

Rafael José Nadim de Lazari *

Data de recebimento: $25 / 03 / 2013$

Data de aprovação: 10/08/2013

\section{RESUMO}

Desenvolver uma consciência constitucional coletiva é medida de ordem no Estado Democrático de Direito, em sua atual fase cooperativa. O problema consiste em saber como materializar isso, razão pela qual, no presente artigo, se tratará de algumas propostas que podem auxiliar na disseminação deste fenômeno. Antes, mister se faz discorrer sobre algumas das concepções de Constituição existentes, para, depois, dar ênfase à de Peter Häberle, a qual melhor se esmiuçará. Ao fim, com o explícito intento de fomentar o saber jurídico constitucional, será emitido parecer com proposta sobre o tema.

\section{ABSTRACT}

Develop a collective constitutional consciousness is a mechanism of order in a Democratic State in its current cooperative phase. The problem is know how mate-

*Advogado, consultor jurídico e parecerista. Doutorando em Direito pela Pontifícia Universidade Católica de São Paulo - PUC/SP. Mestre-bolsista

(CAPES/PROSUP Modalidade 1) em Direito pelo Centro Universitário

Eurípides de Marília - UNIVEM. Professor convidado de Pós-Graduação. Professor convidado da Escola Superior de Advocacia. Professor convidado de curso preparatório para concursos.

E-mail: rafa_scandurra@hotmail.com 
rialize it, why, this article will deal with some proposals that can assist in the dissemination of this phenomenon. Before, will be need talk about some of the existing conceptions of the Constitution, with emphasis on Peter Häberle. In the end, with the explicit purpose of promoting the constitutional legal knowledge, will be given an opinion about the theme.

\section{PALAVRAS-CHAVE}

Peter Häberle. Estado Constitucional Cooperativo. Concepção cultural de Constituição

\section{KEYWORDS}

Peter Häberle. Cooperative Constitutional State. Cultural conception of the Constitution 


\section{INTRODUÇÃO}

A realidade é facilmente perceptível em muitas Instituições de Ensino Superior de direito do país: ministra-se o direito penal por três ou quatro anos (seis ou oito semestres), leciona-se o direito civil do início ao fim, e os processos penal e civil são estudados por (não menos que) cinquenta por cento do tempo de duração do curso. Enquanto isso, ao ensino do direito constitucional, resguarda-se o período de um ano (dois semestres) ou o dobro disso, na melhor das hipóteses.

Em termos práticos, enquanto o aluno estuda todos os livros das partes geral e especial do Código Civil, como pessoas, bens, fatos jurídicos, obrigações, família e sucessões, $p$. ex., deixa de ver temas pertinentes à Lei Fundamental, que não digam respeito às matérias constitucionais propriamente ditas ${ }^{1}$ (direitos fundamentais, organização do Estado e organização dos Poderes), como hermenêutica constitucional aprofundada, finanças públicas, orçamento, ato das disposições constitucionais transitórias, ordens social, econômica e financeira, nuanças acerca de controle de constitucionalidade, etc.

É óbvio que não se pode culpar apenas a "falta de tempo" por esta omissão curricular. Apesar da suma importância da teoria geral dos direitos fundamentais e de suas espécies, por vezes gasta-se tempo desproporcional com seu estudo, em detrimento de outros temas que também deveriam ser passados ao aluno. Afinal, tão importante como explicar ao discente as eficácias vertical e horizontal dos direitos fundamentais, por exemplo, é demonstrar-lhe como funciona, ainda que em termos teóricos, a formação e o pagamento de um precatório/requisição de pequeno valor.

A consequência deste fenômeno imperfeito é um estudo "manco" do direito constitucional, hipertrofiado quanto às matérias propriamente constitucionais, porém raquítico quanto a outros assuntos. $\mathrm{O}$ contexto fica ainda pior se observado que, com isso, o desenvolvimento da consciência constitucional não se procede da maneira que deveria.

Melhor explica-se: é fato que a ciência constitucional - aqui englobando o estudo da Constituição propriamente dita e de comandos normativos que tratam de assuntos constitucionais, como é o caso das Leis $n^{\circ} 9.868 / 99, n^{\circ} 9.882 / 99$ e $n^{\circ}$ 12.562/11, que regulam a ADI, a ADC, a ADO, a ADPF, e a ADI Interventiva, por exemplo, - talvez seja a que mais tenha se desenvolvido nos últimos vinte e cinco anos (processo iniciado com a redemocratização e com o advento da Lei Fundamental de 1988), apesar do direito como um todo também ter se desenvolvido bastante. Basta

1 Ou "matérias tipicamente constitucionais". 
ver os primeiros "Cursos de Direito Constitucional", numa análise visual e fisicamente palpável, lançados em volumes únicos e de espessura mediana, e os estudos atuais, divididos e tematizados em volumes (não raramente mais de um) recheados, com amplo conteúdo jurisprudencial, direito comparado, divergência doutrinária, etc.

Também, impensável seria, há alguns anos, exigir-se do operador do direito que começasse fundamentando sua petição/recurso com a Constituição Federal, e não com a lei. A ideia de "império da lei" decorria do entendimento de que as Cartas Magnas de um país tinham mera força política. Já a Constituição atual, de força jurídica, passou de mera "carta de intenções" para vinculadora das iniciativas pública e privada ${ }^{2}$.

Pior ainda seria admitir que um juiz, um dia, pudesse decidir com base em um princípio não-legislado (à época, sequer norma era um princípio ${ }^{3}$ ).

\footnotetext{
${ }^{2}$ Bem observa BARROSO, Luís Roberto Barroso (Curso de direito constitucional contemporâneo: os conceitos fundamentais e a construção do novo modelo. 2. ed. São Paulo: Saraiva, 2010, p. 197): "Uma das grandes mudanças de paradigma ocorridas ao longo do século XX foi a atribuição à norma constitucional do status de norma jurídica. Superou-se, assim, o modelo adotado na Europa até meados do século passado, no qual a Constituição era vista como um documento essencialmente político, um convite à atuação dos Poderes Públicos".
}

${ }^{3}$ HART, Herbert L. A. (O conceito de direito. 2. ed. Lisboa: Fundação Calouste Gulbenkian, 1994, p. 323-324), não incluía os princípios no campo da normatividade, mas tão-somente as regras, conforme se pode observar: "Não vejo razões nem para aceitar este contraste nítido entre princípios jurídicos e regras jurídicas, nem o ponto de vista de que, se uma regra válida for aplicável a um caso dado, deve, diferentemente de um princípio, determinar sempre o resultado do caso. Não há razões para que um sistema jurídico não deva reconhecer que uma regra válida determina o resultado nos casos em que é aplicável, excepto quando outra regra, julgada como sendo mais importante, seja também aplicável ao mesmo caso. Por isso, uma regra que seja superada, em concorrência com uma regra mais importante num caso dado, pode, tal como um princípio, sobreviver, para determinar o resultado em outros casos, em que seja julgada como sendo mais importante do que outra regra concorrente". Nesse sentido, complementa o autor (O conceito de direito. 2. ed. Lisboa: Fundação Calouste Gulbenkian, 1994, p. 325): "Esta incoerência, verificada na pretensão de que um sistema jurídico consiste tanto em regras de tudo-ou-nada como em princípios não conclusivos, pode ser sanada se se admitir que a distinção é uma questão de grau. Certamente que se pode fazer um contraste razoável entre regras quase-conclusivas, em que a satisfação das respectivas condições de aplicação basta para determinar o resultado jurídico, salvo em poucos exemplos (em que as suas disposições podem entrar em conflito com as de outra regra reputada de maior importância), e princípios geralmente não conclusivos, que se limitam a apontar para uma decisão, mas que podem muito frequentemente não conseguir determiná-la". As palavras de Hart integram um pós-escrito à sua obra, em consequência de ataque efetuado por DWORKIN, Ronald (Levando os direitos a sério. São Paulo: Martins Fontes, 2007, p. 35-43) de que não faria Hart (ou de que tenha feito muito escassamente) a distinção entre regras e princípios. Nesse sentido, afirma Dworkin (Levando os direitos a sério. São Paulo: Martins Fontes, 2007, p. 35-36): "Quero lançar um ataque geral contra o positivismo e usarei a versão de H. L. A. Hart como alvo, quando um alvo específico se fizer necessário. Minha estratégia será organizada em torno do fato de que, quando os juristas raciocinam ou debatem a respeito de direitos e obrigações jurídicos, particularmente naqueles casos difíceis nos quais nossos problemas com esses conceitos parecem mais agudos, eles recorrem a padrões que não funcionam como regras, mas operam diferentemente, como princípios, políticas e outros tipos de padrões. Argumentarei que o positivismo é um modelo de e para um sistema de regras e que sua noção central de um único teste fundamental para direito nos força nos força a ignorar os papéis importantes desempenhados pelos padrões que não são regras" (grifo nosso). 
Nessa frequência, é nítido o paradoxo: o direito constitucional como ciência autônoma se desenvolveu, mas não sua grade de ensino. Com isso, docentes, quando realmente interessados na transferência de conhecimento, se desdobram para vencer o máximo de conteúdo no pouco tempo que lhes é fornecido (não raras vezes aulas-extras são marcadas para cumprir o conteúdo). Nas matérias (assuntos) em que o aluno não é, ao menos, "iniciado", resta-lhe a aprendizagem autodidata, ou o prosseguimento dos estudos numa pós-graduação em sentido amplo ou em sentido estrito. Como essa não é a regra para um bom número de alunos - por absoluta falta de tempo, interesse ou dinheiro -, o resultado é o pouco conhecimento prático do que represente uma jurisdição constitucional, ou o controle preventivo de constitucionalidade das leis e atos normativos, ou de como um bom entendimento de princípios pode servir para vencer uma demanda que, numa análise fria e estrita da lei, é dada como perdida.

Sem mais delongas, este trabalho se debruça sobre a concepção cultural de Constituição, desenvolvida por Peter Häberle, e sua importância para a difusão do saber constitucional. Mais que entender a Constituição como uma conjuntura de fatores normativos, sociológicos, políticos e jurídicos, defende o catedrático de Bayreuth o germinar de uma consciência constitucional coletiva, que abranja tanto os operadores como os não-operadores do direito, como passo fundamental à formação de uma "sociedade aberta" de intérpretes.

Para isso, no tópico seguinte trataremos sobre as diversas concepções de Constituição existentes - dando ênfase, obviamente, à cultural de Häberle -, para, em seguida, poder desenvolver propostas que visem à readequação do ensino da ciência constitucional aos novos tempos do Estado Constitucional Cooperativo ${ }^{4}$.

\footnotetext{
${ }^{4}$ Peter Häberle é um defensor do Estado Constitucional Cooperativo, como método interligador de nações e difusor de cultura. Neste sentido, afirma (El Estado Constitucional. Buenos Aires: Astrea, 2007, p. 148): "Desde un punto de vista analítico, la cooperación entre los pensamientos de las posibilidades, la realidad y las necesidades tendría que proceder "uno tras otro". Primeramente hay que investigar la realidad, después hay que buscar las posibilidades alternativas; éstas deben ser valoradas, a fin de poder identificar las necesidades. Desde este punto de vista, no se trata de estilos sino de etapas del pensamiento que suceden unas a otras. Por lo tanto, se presupone una separación escritcta de los modos de pensamiento que ocurren en cada una de las etapas, la cual difícilmente puede sostenerse en la práctica. $\mathrm{Si}$, por el contrario, se escoge un enfoque, basado en las más recientes reflexiones sobre la tópica, entonces se advierte que no hay sucesión lineal de pasos, sino una relación, de múltiples dimensiones y de alta complejidad, de conjunción, cooperación y contradicción". Inclusive, o autor aventa sobre a possibilidade de integração dos países em desenvolvimento ao Estado Constitucional (EI Estado Constitucional. Buenos Aires: Astrea, 2007, p. 92): "Es posible incluirlos en los contextos de producción y recepción del tipo de Estado constitucional? [...] Es posible integrar ya ahora el Tercer Mundo em el "mundo único" de la "família" de los Estados constitucionales, con todas las particularidades de su especial situación cultural y las siempre presentes asincronías?".
} 


\section{AS CONCEPÇÕES DE CONSTITUIÇÃO, COM ÊNFASE EM PETER HÄBERLE}

São várias as "concepções de Constituição", interpretações à Lei Fundamental consonantes à época e à ocasião em que foram elaboradas. Aqui, trabalharemos na ordem em que se deram, com a sociológica, com a política, com a jurídica, com a normativa, e com a cultural 5 .

Ferdinand Lassalle é o grande expoente da visão sociológica de Constituição, pronunciada em 1863, para intelectuais e operários da antiga Prússia ${ }^{6}$. Segundo o autor, os problemas constitucionais não são problemas jurídicos, mas sim problemas ligados ao poder. Por isso, existiria uma Constituição escrita ou jurídica (como conhecemos) e, ao lado dessa, uma Constituição real ou efetiva (que representa a soma dos "fatores reais de poder" que regem uma determinada nação). Nesse prumo, sendo uma concepção sociológica, esta Constituição efetiva, segundo Lassalle, sempre há de prevalecer sobre a primeira. Se a Constituição escrita não corresponde com a realidade, ela não passa de "uma folha de papel"?.

Por sua vez, Carl Schmitt é o grande entusiasta da concepção política ${ }^{8}$. Com efeito, o autor alemão defende a existência de uma Constituição propriamente dita (apenas aquilo que decorre de uma "decisão política fundamental" que a antecede) e, em segundo plano, de Leis Constitucionais". As duas são formalmente iguais,

\footnotetext{
${ }^{5}$ É óbvio que não são estas as únicas concepções de Constituição existentes. Como outros exemplos, AMARAL, Rafael Caiado (Peter Häberle e a hermenêutica constitucional: alcance doutrinário. Porto Alegre: Sergio Antonio Fabris Editor, 2004, p. 61-64) elenca a Constituição como garantia do status quo econômico e social, de E. Forsthoff, a Constituição como instrumento de governo, de W. Hennis, e a Constituição como conjunto de normas constitutivas para a identidade de uma ordem político-social e do seu processo de realização, de Bäumlin.
}

${ }^{6}$ Consagrada na obra: A essência da Constituição. Rio de Janeiro: Lumen Juris, 2009.

${ }^{7}$ Para o autor (A essência da Constituição. Rio de Janeiro: Lumen Juris, 2009. p. 39): “Onde a constituição escrita não corresponder à real, irrompe inevitavelmente um conflito que é impossível evitar e no qual, mais dia menos dia, a constituição escrita, a folha de papel, sucumbirá necessariamente, perante a constituição real, a das verdadeiras forças vitais do país".

${ }^{8}$ Consagrada na obra: Teoria de la constitución. Salamanca: Alianza Editorial, 1996.

${ }^{9}$ SCHMITT, Carl (Teoria de la constitución. Salamanca: Alianza Editorial, 1996, p. 29-58) ordenou o conceito de Constituição em quatro grupos, a saber, o conceito absoluto, o conceito relativo, o conceito positivo, e o conceito ideal, adotando, contudo, o conceito positivo. Isto porque, para Schmitt (Teoria de la constitución. Salamanca: Alianza Editorial, 1996, p. 34), na realidade, "[...] una Constitución es válida cuando emana de um poder (es decir, fuerza o autoridad) constituyente y se estabelece por su voluntad [...]. La unidad del Reich alemán no descansa em aquellos 181 artículos y em su vigencia, sino em la existencia política del pueblo alemán”. 
mas materialmente distintas. Na primeira, nem tudo o que se encontra na Constituição é fundamental; o que, apesar de estar na Constituição, não for fundamental, serão apenas Leis Constitucionais ${ }^{10}$.

Dando prosseguimento, Hans Kelsen é o grande defensor da concepção jurídica $^{11}$, segundo a qual a Constituição não precisa buscar seu fundamento nem na sociologia nem na política. Para o autor, o fundamento de uma Constituição é estritamente jurídico ${ }^{12}$. Trata-se, veja-se, de uma contraposição diametral ao modo de visão de Lassalle, porque, enquanto naquele primeiro ponto de vista deveria prevalecer a realidade quando esta se confrontasse com a norma, neste, é a norma que deve imperar ainda que seu poder legitimador já não possua o mesmo raciocínio da época da elaboração da Lei Fundamental.

No que atine à visão normativa de Constituição (tese mais arraigada na atualidade do Direito Constitucional), Konrad Hesse, seu grande expoente ${ }^{13}$, reconhece que, de fato, em certos casos, a Constituição jurídica acaba sucumbindo diante da realidade. No entanto, muitas vezes, a Constituição escrita possui uma força normativa capaz de modificar esta realidade ${ }^{14}$; para isso basta que exista "vontade de Constituição" ("Wille zur Verfassung") e não apenas "vontade de poder" no sentido de força ("Wille zur Macht”).

${ }^{10}$ GARCIA-PELAYO, Manoel (Derecho constitucional comparado. Madrid: Ciências Sociales Alianza Editorial, 1999, p. 86) apud AMARAL, Rafael Caiado (Peter Häberle e a hermenêutica constitucional: alcance doutrinário. Porto Alegre: Sergio Antonio Fabris Editor, 2004, p. 60-61) elenca as seguintes diferenças entre Constituição e lei constitucional: "a) o procedimento de reforma é válido para as leis constitucionais, mas não para a constituição, pois uma reforma das decisões políticas fundamentais não suportaria uma emenda, senão uma anulação da constituição; b) as leis constitucionais podem suspender-se (estado de guerra), mas não a constituição como totalidade, pois precisamente a razão de tal suspensão é a manutenção da constituição como totalidade; c) um conflito constitucional não afeta às particularidades, senão às decisões políticas fundamentais; d) o juramento de lealdade à constituição não vincula a ser leal a todos os preceitos constitucionais, que podem mudar seguindo o modo de reforma previsto - e um juramento em branco não tem sentido -, senão que ao que vincula é às repetidas decisões políticas fundamentais".

${ }^{11}$ Consagrada na obra: Teoria pura do direito. 6. ed. São Paulo: Martins Fontes, 2003.

${ }^{12}$ Com isso, tem-se uma das maiores criticas ao positivismo, pois não se determina "o que é a Constituição", mas apenas se preocupa em buscar seu fundamento.

${ }^{13}$ Desenvolvida em: A força normativa da Constituição. Porto Alegre: Sergio Antonio Fabris, 1991.

14 "Embora a Constituição não possa, por si só, realizar nada, ela pode impor tarefas. A Constituição transformase em força ativa se essas tarefas forem efetivamente realizadas, se existir a disposição de orientar a própria conduta segundo a ordem nela estabelecida, se, a despeito de todos os questionamentos e reservas provenientes dos juízos de conveniência, se puder identificar a vontade de concretizar essa ordem" (HESSE, Konrad. A força normativa da Constituição. Porto Alegre: Sergio Antonio Fabris, 1991, p. 19). 
Esta tese é bastante aceita por intermediar o sociologismo de Lassalle ao juridicismo de Kelsen ${ }^{15}$.

Por fim, criada por Peter Häberle, a concepção cultural $^{16}$ entende que a Constituição, em verdade, tem um aspecto sociológico, político e jurídico, remetendo a um conceito de Constituição total (isto é, em todos os aspectos) ${ }^{17}$. Ao mesmo tempo em que uma Constituição é resultante da cultura de um povo, ela também é condicionante dessa mesma cultura com seu surgimento, contribuindo para formação de novos valores ${ }^{18}$.

Tal ângulo de observação parte da premissa de que o direito é um objeto cultural e, como tal, produto da atividade humana ${ }^{19}$. Ora, se a cultura é algo feito por humanos, para ser consumido por outros humanos, significa que uma concepção cultural de direito implica algo que é concebido por humanos para auto-regulação. $\mathrm{O}$ homem cria as regras que vai seguir, e não pode simplesmente modificá-las quando delas não mais precisar, pois, antes disso, deve se certificar de que um número considerável de congêneres também preza pela modificação.

Esta visão é facilmente percebida no direito constitucional. Tanto os países que possuem poucas ou uma Lei Fundamental em seu histórico (como os Estados Unidos, p. ex., cuja única e atual Constituição data de 1787), como os que possuem várias (como é o caso do Brasil, p. ex., com Cartas de 1824, 1891, 1934, 1946, 1967, 1967 e 1988), encontram uma visão cultural para isso: aqueles que possuem uma curta história de Cartas Magnas alegam ou que seu Poder Constituinte Originário

\footnotetext{
${ }^{15}$ Apesar de ser uma explícita resposta à "Constituição como folha de papel", de que tratou Ferdinand Lassalle.

${ }^{16}$ Trabalhada em: El Estado Constitucional. Buenos Aires: Astrea, 2007.

${ }_{17}$ Para Häberle (EI Estado Constitucional. Buenos Aires: Astrea, 2007, p. 86), toda Constituição de um Estado Constitucional "[...] vive en última instancia de la dimensión de lo cultural. La protección de los bienes culturales, las libertades culturales especiales, las cláusulas expresas sobre el "patrimonio cultural" y los artículos generales sobre el Estado de cultura no constituyen sino las manifestaciones particulares de la dimensión cultural general de la Constitución".
}

\begin{abstract}
18 "Al mismo tiempo, la concepción culturalista (kulturwissenschaftlich) de las constituciones gana en capacidad de convicción; la Constitución no es sólo un ordenamiento jurídico para los juristas, los que tienen que interpretarla conforme a las antiguas y a las nuevas reglas de la profesión, sino que actúa esencialmente tambíen como guía para los no juristas: para el ciudadano la Constitución no es sólo un texto jurídico o un "mecansimo normativo"; también es la expresión de un estadio de desarollo cultural, medio para la representación cultural del pueblo ante sí mismo, espejo de su patrimonio cultural y fundamento de suas esperanzas" (HÄBERLE, Peter. El Estado Constitucional. Buenos Aires: Astrea, 2007. p. 86).
\end{abstract}

19 Também, CUNHA JÚNIOR, Dirley da (Curso de direito constitucional. 3. ed. Salvador: JusPODIUM, 2009, p. 89). 
deve ser respeitado ${ }^{20}$ ou que compete ao intérprete manter uma Constituição atempo$\mathrm{ral}^{21}$; já os países que possuem diversas Magnas Cartas em seu histórico alegam que é preciso moldar a Constituição a cada geração, ainda que, para isso, Constituições precisem ser descartadas em nome de outras.

É óbvio que Häberle é criticado pelos adeptos de Hesse (mesmo sendo deste discípulo), por colocar em risco a "Força Normativa da Constituição", defendida por este último ${ }^{22}$. Segundo se aduz, ao acrescentar à mistura constitucional elevadas pitadas de elementos fenomenológicos (notadamente culturais), se torna a Constituição inconsistente para suportar as atribulações de um Estado Democrático, sobretudo se este Estado for recente e ainda em consolidação, como é o caso do Brasil23.

Por outro lado, há se considerar, também utilizando-se dos mesmos argumentos com que se critica Häberle, que é justamente em países de elevada diversidade étnica, social e ideal (como é o caso do Brasil) que a concepção cultural de Constituição deve imperar, para que a democracia seja, para mais que um direito das maiorias, um direito de reconhecimento e proteção às minorias.

Contudo, como aplicar a concepção cultural na readequação do ensino do direito constitucional? Isso já é tema para o próximo tópico.

\section{A IMPORTÂNCIA DA CONCEPÇÃO CULTURAL DE LEI FUNDAMENTAL PARA O DESENVOLVIMENTO DO SABER JURÍDICO CONSTITUCIONAL}

Consoante os preceitos de Constituição cultural, não se pode entendê-la como um conjunto homogeneizado, fruto de ideias absolutamente confluentes após

\footnotetext{
${ }^{20}$ O chamado "interpretativismo", do qual derivam o "textualismo" e o "originalismo", segundo o qual toda interpretação constitucional requer apenas a consideração do texto constitucional à época de sua elaboração (RAMOS, Elival da Silva. Ativismo judicial: parâmetros dogmáticos. São Paulo: Saraiva, 2010, p. 129).

21 O chamado "não-interpretativismo", segundo o qual a vontade do Poder Constituinte Originário deve ser constantemente atualizada aos novos tempos (RAMOS, Elival da Silva. Ativismo judicial: parâmetros dogmáticos. São Paulo: Saraiva, 2010, p. 131-132).

22 Vide notas nos 13 e 14

${ }^{23}$ Häberle, em entrevista concedida a CALLEJÓN, Francisco Balaguer (Um jurista europeu nascido na Alemanha In: VALADÉS, Diego (org.). Conversas acadêmicas com Peter Häberle. São Paulo: Saraiva, 2009, p. 44), demonstra grande preocupação em retirar dos juristas o monopólio definitivo da interpretação constitucional. Para o autor, a perspectiva do desenvolvimento histórico do Estado Constitucional "[...] ensina como todas as forças políticas e os grupos sociais ou grandes figuras como Nelson Mandela na África do Sul realizaram contribuições criativas".
} 
o asseguramento da participação democrática de um Poder Constituinte Originário, como se o simples asseguramento da participação democrática fosse suficiente para representar a vontade dominante. Do contrário, deve-se analisá-la sob viés pluralista, tendo-se em mente que, embora não necessariamente todos os seus dispositivos representem a vontade da maioria, a maneira como se os elaborou e seu contrapeso perante outros dispositivos observou o maior número possível de nuanças dos grupos e classes que a elaboram ${ }^{24}$. "Trocando em miúdos", uma Constituição cultural é, por consequência, pluralista, entendendo-se por "pluralismo" os caracteres advindos tanto da maioria como da minoria ${ }^{25}$. Isso permite concluir, pois, que pluralismo é muito mais que democracia.

Acerca da Constituição pluralista, oportunas as palavras de Häberle, em entrevista concedida a Francisco Balaguer Callejón:

Entender a Constituição como pluralismo pressupõe a clarificação do conceito de pluralismo: é a representação de uma diversidade de interesses e ideias. Essa teoria constitucional pluralista rechaça, portanto, tudo o que podemos caracterizar com a palavra fundamentalismo ou Estado totalitário [...] A Constituição do pluralismo começa sua vida nos fins educativos, nas aulas escolares, mas, ao fim e ao cabo, tem de ser vivida por todos os cidadãos, partidos políticos e grupos privados ${ }^{26}$.

Tomando por base as palavras anteriormente expostas, é possível extrair duas maneiras de se remodelar o ensino do direito constitucional perante um prisma pluralista, e, portanto, cultural.

O primeiro dos meios é o ensino da ciência constitucional por, pelo menos, quatro anos (oito semestres) durante o curso de direito. Este é o tempo necessário para que todo o conteúdo possa ser exteriorizado sem prejuízo da indevida supressão

\footnotetext{
24 "Ante la configuración textual se halla "en el lugar indicado" una multitud diversa de elementos de construcción para la nueva Constitución. Objetivamente luchan entre sí textos clásicos, programas de partidos políticos o asociaciones, pero también logros de la vida de personalidades individuales (por ejemplo, Nelson Mandela)" (HÄBERLE, Peter. Constitución como cultura. Bogotá: Instituto de Estúdios Constitucionales Carlos Restrepo Piedrahita, 2002, p. 101-102).

${ }^{25}$ Em mesmo sentido, AMARAL, Rafael Caiado (Peter Häberle e a hermenêutica constitucional: alcance doutrinário. Porto Alegre: Sergio Antonio Fabris Editor, 2004, p. 143), segundo o qual "[...] o conceito de cultura é uma ideia aberta, pois reflete a sociedade pluralista. A cultura não é produzida apenas por um grupo, mas por todos. A cultura é de todos e para todos [...]. Essa multiplicidade de culturas é garantida pelos textos constitucionais ao assegurarem o pluralismo, a liberdade cultural como princípios constitucionais".

${ }^{26}$ CALLEJÓN, Francisco Balaguer. Um jurista europeu nascido na Alemanha In: VALADÉS, Diego (org.). Conversas acadêmicas com Peter Häberle. São Paulo: Saraiva, 2009, p. 46-47.
} 
de informações do que é explicado, bem como cumprindo todos os dispositivos da Lei Fundamental, as leis constitucionais e o estudo da hermenêutica constitucional.

Assim, sem pretensões exaurientes ao tema, obviamente, interessante seria que um ano inteiro fosse resguardado ao constitucionalismo, à teoria da Constituição, à hermenêutica constitucional, ao preâmbulo constitucional, aos princípios fundamentais (e aqui se fomentaria o estudo dos direitos humanos) e aos direitos e garantias fundamentais. Outro ano seria destinado à organização do Estado, à organização dos Poderes e à defesa do Estado e das instituições democráticas. O terceiro ano seria reservado à tributação e orçamento, à ordem econômica e financeira, à ordem social e ao ato das disposições constitucionais transitórias. O último ano seria resguardado ao controle de constitucionalidade e às especializações do direito constitucional, como o "direito civil constitucional", o "processo civil constitucional", o "direito do trabalho constitucional", dentre outros.

Inclusive, acerca destas matérias autônomas estudadas sob enfoque constitucional, já se pronunciou Häberle, em entrevista concedida a César Landa:

O direito constitucional hoje em dia não só pode ser ensinado e estudado em suas duas dimensões: de um lado, sobre a base das origens da história constitucional e da história do direito (comparação jurídica no tempo); de outro lado, comparadamente num espaço. Mas, também, o direito constitucional pode ser ensinado e estudado como a apresentação do direito constitucional positivo de um país [...]. $E$ de se pensar também a respeito da especialização por matérias eletivas, tais como o direito constitucional cultural, o direito constitucional do trabalho e o direito constitucional da economia. Finalmente, dever-se-ia tratar principalmente da posição e da função especial do Tribunal Constitucional $[\ldots]^{27}$

Apesar da Constituição brasileira, mesmo prolixa, ser relativamente curta, com não mais que duzentos e cinquenta comandos, há se lembrar que o conteúdo contido em cada texto é amplíssimo (a norma, veja-se, excede ao texto), que a Lei Fundamental pátria é constantemente alterada (não demorará muito para se chegar a uma centena de Emendas Constitucionais), que existe uma explicação metajurídica para cada comando constitucional e que nem tudo que diz respeito à ciência constitucional está, efetivamente, na Constituição.

Interessante, ainda, para o enriquecimento do conteúdo compartilhado, seria o estudo da jurisprudência, da jurisdição constitucional e do direito comparado.

\footnotetext{
${ }^{27}$ LANDA, César. Reforma do ensino do Direito Constitucional In: VALADÉS, Diego (org.). Conversas acadêmicas com Peter Häberle. São Paulo: Saraiva, 2009, p. 72.
} 
Seria extremamente interessante que os docentes tivessem tempo de proceder, com seus alunos, à leitura e à compreensão - por trabalhos, debates e seminários - de decisões paradigmáticas emanadas pelo Supremo Tribunal Federal, tais como sobre verticalização, sobre omissões legislativas inconstitucionais, sobre aborto de fetos anencefálicos, sobre a validade da "Lei da Ficha Limpa", sobre a constitucionalidade do Exame da OAB, dentre outras.

Já o segundo dos meios seria o ensino da ciência constitucional de maneira pré-universitária, bem como em cursos não estritamente jurídicos.

Com efeito, Häberle defende a "sociedade aberta dos intérpretes da Constituição" em obra homônima ${ }^{28}$.

Para o autor, somente se pode emplacar um conceito de "Constituição total" caso se permita que diversos sejam os agentes envolvidos na formação de uma consciência constitucional. Como consequência, almeja-se retirar do Poder Judiciário a última palavra em sede de interpretação dos comandos legais para permitir que, também, outros entes o façam, prévia ou concomitantemente, à apreciação pelo julgador.

O catedrático de Bayreuth apresenta um "catálogo provisório" 29 dos intérpretes da Constituição, formado: 1) pelas funções estatais ${ }^{30}$; 2) pelos participantes do processo de decisão nos casos " $a$ " e " $b$ " vistos anteriormente na nota explicativa $n^{o} 30^{31}$; 3) pela opinião pública democrática e pluralista e o processo político

\footnotetext{
${ }^{28}$ HäBERLE, Peter. Hermenêutica constitucional: a sociedade aberta dos intérpretes da Constituição: contribuição para a interpretação pluralista e "procedimental” da Constituição. Porto Alegre: Sergio Antonio Fabris, 1997.

${ }^{29}$ É utilizada, sabiamente, esta expressão: “catálogo provisório" (HÄBERLE, Peter. Hermenêutica constitucional: a sociedade aberta dos intérpretes da Constituição: contribuição para a interpretação pluralista e “procedimental” da Constituição. Porto Alegre: Sergio Antonio Fabris, 1997, p. 20).
}

30 "[...] a) na decisão vinculante (da Corte Constitucional): decisão vinculante que é relativizada mediante o instituto do voto vencido; b) nos órgãos estatais com poder de decisão vinculante, submetidos, todavia, a um processo de revisão [...]" (HÄBERLE, Peter. Hermenêutica constitucional: a sociedade aberta dos intérpretes da Constituição: contribuição para a interpretação pluralista e "procedimental" da Constituição. Porto Alegre: Sergio Antonio Fabris, 1997, p. 20-21).

\footnotetext{
31 “[...] a) o requerente ou recorrente e o requerido ou recorrido, no recurso constitucional [...]; b) outros participantes do processo, ou seja, aqueles que têm direito de manifestação ou de integração à lide [...], ou que são, eventualmente, convocados pela própria Corte Constitucional [...]; c) pareceristas ou experts [...]; d) peritos e representantes de interesses nas audiências públicas do Parlamento [...], peritos nos Tribunais, associações, partidos políticos (frações parlamentares), que atuam, sobretudo, mediante a "longa manus" da eleição de juízes; e) os grupos de pressão organizados [...]; f) os requerentes ou partes nos procedimentos administrativos de caráter participativo" (HÄBERLE, Peter. Hermenêutica constitucional: a sociedade aberta dos intérpretes da Constituição: contribuição para a interpretação pluralista e "procedimental” da Constituição. Porto Alegre: Sergio Antonio Fabris, 1997, p. 21-22).
} 


\title{
como grandes estimuladores ${ }^{32}$; e 4) pela doutrina constitucional ${ }^{33}$.
}

Fazendo uma adaptação livre do sistema jurídico brasileiro, se está falando, a título não-exauriente, dos legitimados para ação direta de inconstitucionalidade e ação declaratória de constitucionalidade do art. 103, $\mathrm{CF}^{34}$; da reclamação constitucional do art. 103-A, $\S 3^{035}$; do Conselho Nacional de Justiça do art. 103-B ${ }^{36}$; do "amicus curiae" ${ }^{37}$, do plebiscito e do referendo dos incisos I e II, respectivamente, do

\begin{abstract}
32 "[...] media (imprensa, rádio, televisão, que, em sentido estrito, não são participantes do processo, o jornalismo profissional, de um lado, a expectativa de leitores, as cartas de leitores, de outro, as iniciativas dos cidadãos, as associações, os partidos políticos fora do seu âmbito de atuação organizada [...], igrejas, teatros, editoras, as escolas da comunidade, os pedagogos, as associações de pais" (HÄBERLE, Peter. Hermenêutica constitucional: a sociedade aberta dos intérpretes da Constituição: contribuição para a interpretação pluralista e "procedimental" da Constituição. Porto Alegre: Sergio Antonio Fabris, 1997, p. 22-23).
\end{abstract}

33 "[...] ela tem um papel especial por tematizar a participação de outras forças e, ao mesmo tempo, participar nos diversos níveis" (HÄBERLE, Peter. Hermenêutica constitucional: a sociedade aberta dos intérpretes da Constituição: contribuição para a interpretação pluralista e "procedimental" da Constituição. Porto Alegre: Sergio Antonio Fabris, 1997, p. 23).

34 "Art. 103. Podem propor a ação direta de inconstitucionalidade e a ação declaratória de constitucionalidade: I - o Presidente da República; II - a Mesa do Senado Federal; III - a Mesa da Câmara dos Deputados; IV - a Mesa de Assembleia Legislativa ou da Câmara Legislativa do Distrito Federal; V - o Governador de Estado ou do Distrito Federal; VI - o Procurador-Geral da República; VII - o Conselho Federal da Ordem dos Advogados do Brasil; VIII - partido político com representação no Congresso Nacional; IX - confederação sindical ou entidade de classe de âmbito nacional".

35 "Art. 103-A. [...] §3 Do ato administrativo ou decisão judicial que contrariar a súmula aplicável ou que indevidamente a aplicar, caberá reclamação ao Supremo Tribunal Federal que, julgando-a procedente, anulará o ato administrativo ou cassará a decisão judicial reclamada, e determinará que outra seja proferida com ou sem a aplicação da súmula, conforme o caso".

36 "Art. 103-B. O Conselho Nacional de Justiça compõe-se de 15 (quinze) membros com mandato de 2 (dois) anos, admitida 1 (uma) recondução, sendo: I - o Presidente do Supremo Tribunal Federal; II - um Ministro do Superior Tribunal de Justiça, indicado pelo respectivo tribunal; III - um Ministro do Tribunal Superior do TrabaIho, indicado pelo respectivo tribunal; IV - um desembargador de Tribunal de Justiça, indicado pelo Supremo Tribunal Federal; V - um juiz estadual, indicado pelo Supremo Tribunal Federal; VI - um juiz de Tribunal Regional Federal, indicado pelo Superior Tribunal de Justiça; VII - um juiz federal, indicado pelo Superior Tribunal de Justiça; VIII - um juiz de Tribunal Regional do Trabalho, indicado pelo Tribunal Superior do Trabalho; IX - um juiz do trabalho, indicado pelo Tribunal Superior do Trabalho; X - um membro do Ministério Público da União, indicado pelo Procurador-Geral da República; XI - um membro do Ministério Público estadual, escolhido pelo Procurador-Geral da República dentre os nomes indicados pelo órgão competente de cada instituição estadual; XII - dois advogados, indicados pelo Conselho Federal da Ordem dos Advogados do Brasil; XIII - dois cidadãos, de notável saber jurídico e reputação ilibada, indicados um pela Câmara dos Deputados e outro pelo Senado Federal".

${ }^{37}$ Dentre outros dispositivos em que se cita o "amigo da Corte", se pode mencionar o art. $482, \S^{\circ}$, do Código de Processo Civil: "O relator, considerando a relevância da matéria e a representatividade dos postulantes, poderá admitir, por despacho irrecorrivel, a manifestação de outros órgãos ou entidades". 
art. $14, \mathrm{CF}^{38}$; da iniciativa para apresentar projetos de lei prevista no art. $61, \S 2^{039}$; e, em esfera muito mais abrangente, da jurisdição constitucional.

Ora, se na hipótese anteriormente vista se trabalhou com a necessidade do desenvolvimento de uma consciência constitucional pelos operadores do direito, há se lembrar que tal consciência, para que a concepção cultural de Lei Fundamental seja efetiva, deve atingir também os não-operadores do direito. Assim, se juristas devem aderir ao pluralismo, também o devem matemáticos, economistas, médicos, professores ou mesmo quem não tenha qualquer diploma de curso superior, mas esteja atento às questões nevrálgicas que este país enfrenta diariamente.

Uma importante maneira de fomentar isso é a determinação do ensino da ciência constitucional em cursos não-jurídicos (embora de maneira simplificada, obviamente), bem como no ensino médio (ensino secundário), caso este último em que a disciplina não seria a de direito constitucional propriamente dita, mas de história, e/ou filosofia, e/ou sociologia, e/ou lógica relacionadas à Constituição.

Nesse sentido, Häberle, em entrevista concedida a César Landa, considera que:

[...] os estudantes da ciência constitucional devem aprender a história e a filosofia. Também os princípios políticos dos tipos do Estado Constitucional, bem como o direito constitucional de suas realidades nacionais concretas ${ }^{40}$.

É óbvio que não estamos falando da exigência de que um estudante de quinze anos ou um catedrático de psicologia, $p$. ex., entendam de controle de constitucionalidade ou de estado de sítio/estado de defesa; no entanto, de direitos fundamentais, ao menos, todos devem ter uma consciência mínima.

Todos devem saber que homens e mulheres são iguais em direitos e obrigações (art. $5^{\circ}, \mathrm{I}, \mathrm{CF}$ ), que ninguém será submetido à tortura nem a tratamento degradante (art. $5^{\circ}, \mathrm{III}, \mathrm{CF}$ ), que o Estado prestará assistência jurídica integral e gratuita aos que comprovarem a insuficiência de recursos (art. $5^{\circ}$, LXXIV, CF), que o registro

\footnotetext{
38 "Art. 14. A soberania popular será exercida pelo sufrágio universal e pelo voto direto e secreto, com valor igual para todos, e, nos termos da lei, mediante: I - plebiscito; II - referendo; [...]".

39 “Art. 61. [...] $2^{\circ} \mathrm{A}$ iniciativa popular pode ser exercida pela apresentação à Câmara dos Deputados de projeto de lei subscrito por, no mínimo, um por cento do eleitorado nacional, distribuído pelo menos por cinco Estados, com não menos de três décimos por cento dos eleitores de cada um deles".

${ }^{40}$ LANDA, César. Reforma do ensino do Direito Constitucional In: VALADÉS, Diego (org.). Conversas acadêmicas com Peter Häberle. São Paulo: Saraiva, 2009, p. 74.
} 
civil de nascimento e a certidão de óbito são gratuitos para os reconhecidamente pobres (art. 50, LXXVI, "a" e "b”, CF), que a educação e a saúde são direitos sociais (art. 6, caput, CF), que a lei não poderá estabelecer distinções entre brasileiros natos e naturalizados (art. 12, $\S 2^{\circ}, \mathrm{CF}$ ), que o voto é facultativo para os maiores de dezesseis e menores de dezoito anos (art. 14, §, III, “c”, CF), ou que é vedada a cassação de direitos políticos (art. 15, caput, CF), dentre alguns exemplos.

É imperioso que haja uma "popularização" do Direito Constitucional - utilizando-se o termo "popularização" na melhor das intenções, isto é, sem qualquer correlação com o desprezível "populismo" -, num movimento parecido com o que fez a Lei ${ }^{\circ} 12.291 / 10$, ao determinar que estabelecimentos comerciais disponibilizem aos seus clientes ao menos um exemplar do Código de Defesa do Consumidor. Não seria má ideia fazer o mesmo com a Constituição Federal.

Em prol da disseminação da consciência constitucional, como meio de reformular o saber jurídico constitucional sob a égide da concepção cultural (e pluralista) de Lei Fundamental, pois é preciso que o ensino do direito constitucional saia das cátedras sociais aplicadas e invada salas de aula, estabelecimentos comerciais, estabelecimentos recreativos, redes sociais etc. Não há nada mais interessante, nesse sentido, que um debate sobre a viabilidade do aborto do feto anencefálico pelo $f a$ cebook, p. ex.

Não que o fomento à concepção cultural de Constituição seja um fim em si mesmo, isto é, não se quer uma mera "consciência" constitucional (tal como não se quer uma mera "consciência" ambiental, nem uma mera "consciência" social, noutros exemplos). Conforme já dito outrora, quando se falou do direito como objeto cultural, há de se lembrar que o objetivo desta consciência pluralista pretende mais que o mero campo de debates. Intenta, isso sim, a própria produção da Constituição que rege um povo.

\section{CONSIDERAÇÕES FINAIS}

Por todo o exposto, as conclusões que se extraem são as seguintes:

1) É fundamental ter em mente que o direito, como objeto cultural, é produzido pelo homem para sua própria regulação. Regra diferente não há para a Constituição da República, portanto. Aliás, a Constituição é justamente o ponto máximo de representação cultural de uma sociedade pluralista (lembrando que pluralismo é muito mais que democracia);

2) O momento atual é de desenvolvimento da concepção cultural de Constituição, defendida por Peter Häberle, sendo interessante sua utilização na reforma do ensino do direito constitucional; 
3) Uma das medidas em prol dessa reforma é o estabelecimento do ensino da ciência constitucional por, pelo menos, quatro anos (oito semestres), para que todo o conteúdo seja explicado, e para que o docente possa explorar mais os debates que o direito constitucional proporciona; e

4) A segunda medida é o ensino do direito constitucional (de maneira simplificada, é verdade) tanto em cursos não-jurídicos como no grau médio (ou secundário) de aprendizagem. Se Häberle defende a existência de uma "sociedade aberta de intérpretes da Constituição", há que se lembrar que esta não é formada apenas por juristas, por isso essa ideia.

De toda maneira, é óbvio que não se almeja exaurir o debate desde já proposto. Certamente, muitos falarão que o mesmo tipo de atenção deve ser dispensada ao direito previdenciário, ao direito eleitoral, ao direito administrativo e ao direito tributário, p. ex., que, como regra, também são estudados em apenas um ano (dois semestres) da graduação.

Não que se despreze a importância destas matérias (muito pelo contrário), mas é necessária a popularização do direito constitucional em prol do desenvolvimento de uma consciência constitucional coletiva. Algo que não se restrinja às cátedras jurídicas, servindo como instrumento de puro intelectualismo barato nas mãos de poucos que adoram dessa condição se valer.

\section{REFERÊNCIAS}

AMARAL, Rafael Caiado. Peter Häberle e a hermenêutica constitucional: alcance doutrinário. Porto Alegre: Sergio Antonio Fabris Editor, 2004.

BARROSO, Luís Roberto. Curso de direito constitucional contemporâneo: os conceitos fundamentais e a construção do novo modelo. 2. ed. São Paulo: Saraiva, 2010.

CALLEJÓN, Francisco Balaguer. Um jurista europeu nascido na Alemanha In: VALADÉS, Diego (org.). Conversas acadêmicas com Peter Häberle. São Paulo: Saraiva, 2009.

CUNHA JÚNIOR, Dirley da. Curso de direito constitucional. 3. ed. Salvador: JusPODIUM, 2009.

DWORKIN, Ronald. Levando os direitos a sério. São Paulo: Martins Fontes, 2007.

HÄBERLE, Peter. El Estado constitucional. Buenos Aires: Astrea, 2007. 
. Constitución como cultura. Bogotá: Instituto de Estúdios Constitucionales Carlos Restrepo Piedrahita, 2002.

Hermenêutica constitucional: a sociedade aberta dos intérpretes da Constituição: contribuição para a interpretação pluralista e "procedimental" da Constituição. Porto Alegre: Sergio Antonio Fabris, 1997.

HART, Herbert L. A. O conceito de direito. 2. ed. Lisboa: Fundação Calouste Gulbenkian, 1994.

HESSE, Konrad. A força normativa da Constituição. Porto Alegre: Sergio Antonio Fabris, 1991.

KELSEN, Hans. Teoria pura do direito. 6. ed. São Paulo: Martins Fontes, 2003.

LANDA, César. Reforma do ensino do Direito Constitucional In: VALADÉS, Diego (org.). Conversas acadêmicas com Peter Häberle. São Paulo: Saraiva, 2009.

LASSALLE, Ferdinand. A essência da Constituição. 9. ed. Rio de Janeiro: Lumen Juris, 2009.

RAMOS, Elival da Silva. Ativismo judicial: parâmetros dogmáticos. São Paulo: Saraiva, 2010.

SCHMITT, Carl. Teoria de la constitución. Salamanca: Alianza Editorial, 1996.

VADE mecum saraiva. 15. ed. São Paulo: Saraiva, 2013. 